\title{
Attention deficit hyperactivity disorder amongst today's NCAA student-athletes
}

\begin{abstract}
Mental health disorders amongst National Collegiate Athletic Association (NCAA) student-athletes is a major concern for colleges, universities, coaches, athletic trainers and the colleges and universities that these student-athletes attend. As a result, many student-athletes are suffering from the lack of support system to aid them during their college career. The purpose of this conceptual paper is to introduce Attention Deficit Hyperactivity Disorder (ADHD) and discuss the effects it can have on a student-athlete as well as the improvements that can be made by providing an appropriate support system. Practical implication from the paper can contribute towards the growing awareness of mental health disorders among NCAA student-athletes, in particular ADHD. Coaches, athletic trainers, athletic administrators, counselors and advisors can learn to understand the daily constraints student-athletes can face in dealing with this mental health disorder. Strategies for improving and assessing the current mental well-being of student-athletes suffering from ADHD are discussed.
\end{abstract}

Keywords: Learning disability, attention deficit hyperactive disorder, intercollegiate athletics, student-athletes
Volume I Issue 3 - 2017

\section{Heath Hooper}

Shorter University, USA

Correspondence: Heath Hooper, Shorter University, USA, Email hhooper@shorter.edu

Received: August 23, 2017 | Published: September 05, 2017
Abbreviations: NCAA, national collegiate athletic association; $\mathrm{ADHD}$, attention deficit hyperactivity disorder; IDEA, individuals with disabilities education act; LDNOS, learning disorder not otherwise specified

\section{Introduction}

According to the National Center for Education Statistics, ${ }^{1}$ in 2011 2012 , approximately $11 \%$ of college undergraduates reported having or have suffered from a learning disability, up from $10.9 \%$ in 2008 . Individuals with Disabilities Education Act (IDEA) defines a learning disability as a disorder in one or more of the basic psychological processes used to understand and/or using language (written or spoken) which may be difficult for an individual to have the ability to listen, speak, think, write, read, spell or do mathematical calculations. Learning disabilities are recognized to be neurological within all individuals who suffer from one or more. ${ }^{2}$ Diagnosis of a learning disability requires there are deficits in functioning in a particular area that would not be predicted by a student's measured intelligence, level of educational development, or individual's age. ${ }^{2}$ Identifying learning disabilities amongst student-athletes can vary amongst the more common disabilities: Reading disorder (Dyslexia), Mathematics Disorder (Dyscalculia), Disorder of Written Language (Dysgraphia), Learning Disorder Not Otherwise Specified (LD NOS) and Attention Deficit Hyperactivity Disorder (ADHD). ${ }^{2}$ Student-athletes are among the greater number of the undergraduate population that suffer from a learning disability or suffers from a type of learning disability but never medically diagnosed with a disability. ${ }^{3}$ The following research analysis will identify the effects Attention Deficit Hyperactivity Disorder (ADHD) has on collegiate student-athletes, techniques currently used to aid student-athletes cope with ADHD and specific strategies college and university athletic departments need to implement to improve student-athlete learning disability cases.

\section{Attention-deficit hyperactivity disorder}

Individuals suffering from the learning disability, ADHD, have difficulties with maintaining attention at various times and managing their specific impulses. In order to be diagnosed with ADHD for either the inattention or hyperactivity, an individual must exhibit five out of the nine symptoms listed below for at least six months. These symptoms must also be severe enough to disrupt the student-athlete's quality of life. ${ }^{4}$ The three core symptoms are:

\section{a. Inattention \\ b. Hyperactivity \\ c. Impulsivity}

Each of these core systems is associated with additional symptoms; however, these symptoms are most of the time noticed by studentathletes in a setting in which he/she is listening to a lecture, finishing homework or listening to their coach.

The following table focuses on the symptoms associated with each of the core symptoms (Table 1 ). ${ }^{4}$ From examining the table, it is evident there are numerous areas of an individual that are affected from the learning disorder known as ADHD. Student-athletes diagnosed or suffering from ADHD are considered "problem children" in whom they lack normality in many areas needed to be successful in academics and athletics as a collegiate student-athlete. ${ }^{2}$ Student-athletes being identified with symptoms of ADHD will suffer from academic difficulties, decisions and issues regarding the use of medication and most importantly balancing the responsibilities of a student-athlete. ${ }^{5}$ Colleges and universities across the country have identified and diagnosed $2 \%$ of the total United States undergraduate population or 394,500 students suffering from ADHD. ${ }^{6}$ These students are entitled to ask for special academic treatment under federal disability law as 
long as they are medically diagnosed as suffering from ADHD. ${ }^{6}$ The typical diagnosis for ADHD occurs at the childhood level, however it is not established until early adulthood due to the severity of the symptoms. ${ }^{4}$

Table I Symptoms associated with each of the core symptoms

\begin{tabular}{lll}
\hline \multicolumn{2}{l}{ Core adhd symptoms } & \\
\hline inattention & Hyperactivity/impulsivity \\
\hline I & Fails to give close attention to detail and make careless mistakes & Fidgets with hands or feet. \\
2 & Difficulty sustaining attention on tasks. & Leaves seat when it is inappropriate. \\
3 & Does not seem to listen when spoken to directly. & Excessively active and/or feelings of restlessness. \\
4 & Does not fully complete tasks or follow through on instructions. & Difficulty with engaging in leisure activities quietly. \\
5 & Problems with or organizing tasks and activities. & On-the-go all the time. \\
6 & Avoid tasks that require mental effort. & Talks excessively. \\
7 & Loses things necessary for tasks and activities. & Blurts things out while in conversation. \\
8 & Easily distracted by extraneous stimuli. & Difficulty waiting turn. \\
9 & Forgetful in daily activities. & Interrupts or intrudes on others activities or conversations.
\end{tabular}

\section{Managing the student-athlete with ADHD}

The second largest disability subgroup on campus behind specific learning disabilities is students with ADHD. ${ }^{7}$ Many researchers believe that the rise in students with ADHD is due to the use of stimulants taken to increase their academic performance. ${ }^{8}$ It is noted through previous research that students with ADHD are at risk of experiencing emotional difficulties, dropping out of school and likely to underperform in the classroom setting; more so these students tend to have lower Grade Point Averages (GPA) and more likely to be placed on academic probation. ${ }^{9}$

For many students, sports serve as a natural remedy for ADHD and the symptoms associated with the mental disorder. ${ }^{3}$ Statistics are even evident through research; there is a statistically significant decrease in anxiety and depression amongst ADHD student-athletes that exhibit high levels of sport participation. ${ }^{10}$ The NCAA also works to help student-athletes prior to enrolling in college. The NCAA, Divisions I and II can allocate accommodations for student-athletes initial eligibility that are suffering from education-impacting disabilities such as ADHD: (NCAA, 2012).

A. NCAA Division I: student-athletes must graduate within eight semesters of first-time enrollment in order to access the accommodation:

B. Use up to three additional approved core courses taken before full-time enrollment in college.

C. NCAA Division II: a student may access the following accommodation:

D. Use any approved core courses taken before full-time enrollment in college.

E. NCAA Division I \& II: a student may access the following accommodations:

F. Use courses for students with education-impacting disabilities that are designated on the high school's list of NCAA courses.

G. May take a nonstandard test to satisfy test score requirements.
These accommodations give learning impaired student-athletes a couple of alternatives in their initial eligibility endeavors towards enrolling as a collegiate student-athlete and then working towards completion of a degree. Student-athletes are a group of students that have many different experiences, pressures and time constraints than a traditional undergraduate college student. Student-athletes are a population that has special needs and pressures that they come into contact with on a daily basis. ${ }^{11}$ The stereotypes surrounding studentathletes intensify if he or she is diagnosed with a learning disability. ${ }^{12}$ The playing field is usually the one place where a student-athlete with ADHD can overcome the obstacles faced during a normal day. Off the playing field, it is much more difficult for student-athletes, especially in their academia. These difficulties can lead to further academic difficulties and even emotional and social dissatisfaction. ${ }^{13}$ Even though there are adequate faculty members, coaches, academic advisors and student-services available to assist these studentathletes, a lack of not knowing or not understanding how to meet the needs of ADHD students is evident in college settings. Academic support services need to constantly encourage members of the college community to meet the needs of these student-athletes with learning disabilities.

\section{Recognizing and improving ADHD amongst student- athletes}

There are several difficulties student-athletes encounter while suffering from a learning disability or ADHD: deficits in study skills,

a. Problems with organizational skills

b. Difficulties with social interaction

c. Deficits in specific academic areas such as composition, reading, writing and mathematics,

d. low self-esteem

e. Higher drop-out rates. ${ }^{13}$

Fortunately, for collegiate student-athletes, there are numerous individuals close enough to a student-athlete to recognize if he/she 
may be suffering from a learning disability. Coaches, counselors, faculty, academic support staff and athletic trainers are the initial caregivers and recognizers to identifying a learning disability in student-athletes. ${ }^{2}$ By indicating a sense of concern or direction can help a student-athlete take steps towards improving or even overcoming a particular learning disability. Asking questions to a student-athlete you suspect could have a learning disability is the initial step; these questions can include:

i. What concerns do you have currently about your academics and athletics?

ii. Did you or have you received tutoring in high school or college?

iii. How easy or difficult is it for you to manage your time as a student-athlete?

iv. How is your ability to pay attention?

All of these questions plus many others can help formulate an extensive assessment on a student-athlete's learning ability. ${ }^{2}$ Most colleges and universities have an academic support staff and office available to student-athletes in need of extra tutoring, guidance and counseling of specific problems including learning disabilities and ADHD. College academic support staffs have persons readily available in all areas such as writing, composition, mathematical services and other course specific studies. Study hall is a technique used by coaches and athletic departments to monitor and make sure student-athletes have an allotted amount of time to complete course homework. Student-athletes with ADHD can take advantage of study hall or use their study hall time to meet with an academic support staff member. Another technique colleges and universities have employed is known as a learning assistance program which learning specialists provide support to students and student-athletes suffering from a learning disability. ${ }^{14}$ A learning assistance program's top four responsibilities are teaching learning strategies, time management skills, organizational skills and working with student-athletes with learning disabilities. ${ }^{14}$ This service or form of service is a technique that can assess the difficulties a student or student-athlete may be suffering from and guide them in the right direction of achieving success in areas of improvement.

The N4A (2007) conducted a research study in which 168 athletic academic support personnel who were representative of 45 different athletic conferences within the NCAA Division I level. The results of the survey revealed that $45 \%$ of participants had a program specifically for student-athletes with learning disabilities (N4A, 2007). Three of the institutions stated that they had over 100 student-athletes with ADHD, 24 respondents revealed having 20-29 student-athletes at their institution with learning disabilities and 21 individuals expressed that their institutions had 10-19 student-athletes with ADHD. ${ }^{15}$ Learning specialists also expressed concerns of student-athletes with ADHD as follows:

I. lack of knowledge associated with student-athletes

II. athletic coaches did not understand learning disabilities

III. Percentage of student-athletes that were being referred to be tested for a learning disability. ${ }^{15}$

Further research includes a study conducted by the NCAA in 2009 of the behaviors and resources of NCAA Division I member institutions regarding academic support success. The results of this survey revealed that $3 \%$ of all NCAA Division I student-athletes have been assessed for learning disabilities. ${ }^{15}$ The NCAA $^{15}$ also reported a statistically significant difference regarding the portions of studentathletes assessed for learning disabilities in Division I Football Bowl Series (FBS) and Football Championship Series (FCS) in which more student-athletes in FBS were being assessed for ADHD rather than FCS student-athletes. ${ }^{15}$

After a certified medical doctor or counselor has completed a formal evaluation, the collegiate athletic department and academic support staff or learning assistance program can begin devising strategies and accommodations for student-athletes under the Americans with Disabilities Act of 1990. This law provides equal access to services for persons with disabilities. ${ }^{2}$ Student-athletes will meet with a member of the learning assistance program to identify appropriate individual accommodations that will address and improve specific functional limitations. ${ }^{2}$ Possible accommodations can include but are not limited to scheduling classes, materials provided in accessible formats, pre-registration priority, in class adjustments such as individual testing or extra-time on tests and/or substitution exemptions on specific courses. ${ }^{2}$ These accommodations however will not provide a student-athlete with a reduced curriculum completion, as he or she is still responsible for completing all requirements of progress towards degree. Student-athletes with learning disabilities will have recommendations in which the individual will adhere to a comprehensive model of academic support, personal and social support, collaboration, self-advocacy and leadership opportunities in which the student-athlete will work towards meeting the needs of all areas mentioned above. ${ }^{12}$ Furthermore, there are three additional strategies recommended to student-athletes suffering from ADHD or another form of a learning disability:

a) Tutoring

b) Counseling

c) College success strategies.

Tutoring services are the ideal academic support for student-athletes suffering from ADHD. ${ }^{2}$ The tutor is able to work directly one-on-one with the student-athlete on areas such as time management, study skills, learning assessment, writing strategies and self-confidence. Hock $^{16}$ looked specifically at the benefits of a tutoring program for student-athletes with a learning disability and found that studentathletes with a learning disability who received tutoring performed as well as their classmates (non-learning disability students) in an English 101 course. The second strategy area is counseling recommended for any student or student-athlete for various reasons. Many symptoms and areas of negativity are discussed in counseling which can lead to improvements in all facets of a student-athlete's life. The final strategy area is a college success strategy, which incorporates a university learning assistance program and academic support unit. This area can be discussed one-on-one with individual student-athletes or with a group. The focus is on study skills, understanding a studentathlete's daily life, accountabilities to athletics and academics and time management skills needed to encompass all responsibilities. ${ }^{14}$ All of these strategies mentioned can gradually improve a studentathlete's learning disability. The ability to overcome and improve daily pressures and disabilities takes a group effort and an individual effort to encompass all facets of improvisation. 


\section{Conclusion}

Learning disabilities and ADHD are a growing issue in collegiate athletics in which student-athletes are not being identified as an individual in need of extra accommodations. Campus professionals need to be aware of the most useful approaches for effectively identifying student-athletes that are suspected of learning disabilities in a timely manner. ${ }^{2}$ The accommodations mentioned and counseling services to these students are increasing and are making a difference in their everyday pressures as a student-athlete. ${ }^{5}$ Collegiate athletic department learning assistance programs need to be implemented into every student-athlete's daily routine once he or she has been diagnosed by a certified examiner of suffering from a learning disability. Strategies for assessing and improving disabilities are readily improving; however, all personnel in the athletic department and university faculty and staff must work together in understanding and assisting a student-athlete's transition successfully. ${ }^{17}$

\section{Acknowledgements}

None.

\section{Conflict of interest}

Author declares there is no conflict of interest in publishing the article.

\section{References}

1. National Center for Education Statistics. Profile of Undergraduates in U.S. Postsecondary Education Institutions: 2012;2003-2004 (NCES 2006-184).

2. Etzel EF, Carter JE. Counseling and psychological services for college student-athletes. Fitness Information Technology. USA; 2009.

3. Perrin AE, Jotwani VM. Addressing the unique issues of student-athletes with ADHD. J Fam Pract. 2014;63(5):E1-E9.

4. Vahia VN. Diagnostic and statistical manual of mental disorders 5: A quick glance. Indian J Psychiatry. 2013;55(3):220-223.

5. US Department of Education. Twenty-eighth annual report to Congress on in implementation of the individuals with Disabilities Education Act. Westa. USA; 2006.
6. Vickers MZ. Accommodating college students with learning disabilities: $\mathrm{ADD}, \mathrm{ADHD}$ and dyslexia. Pope Center Series on Higher Education, USA; 2010.

7. Harbour W. The 2004 AHEAD Survey of Higher Education Disability Service Providers. Association on Higher Education and Disability. USA; 2004.

8. Advokat C, Martino L, Guidry D. Licit and illicit use of attention-deficit hyperactivity (ADHD) medication by college students. J Am Coll Health. 2008;56(6)601-606.

9. Glutting JJ, Youngstrom E, Watkins M. ADHD and college students: Exploratory and confirmatory factor structures using student and parent data. Psychol Assess. 2005;17(1):44-55.

10. Kiluk BD, Weden S, Culotta VP. Sport participation and children with ADHD. J Atten Disord. 2009;12(6):499-506.

11. Gayles JG. The student athlete experience. New Directions for Institutional Research. 2009;144:33-41.

12. Clark M, Parette P. Student-athletes with learning disabilities: A model for effective supports. College Student Journal. 2002;36(1):47-61.

13. Skinner ME, Lindstrom BD. Bridging the gap between high school and college: Strategies for the successful transition of students with learning disabilities. Preventing School Failure. 2003;47(3):132-138.

14. Weiss MP. Supporting student-athletes with disabilities: A case study. Journal of Postsecondary Education and Disability. 2011;24(2):161-163.

15. National Collegiate Athletic Association. Student-athlete academic support services at division I institutions (Preliminary Results). NCAA Research. USA; 2009.

16. Hock MF. The effectiveness of an instructional tutoring model and tutor training on the academic performance of under-prepared college studentathletes (Doctoral dissertation, University of Kansas, 1998). Dissertation Abstracts International. 1998;59(09A):3335.

17. NCAA. Students with education-impacting disabilities. National Eligibility Center, Indianapolis, USA; 2012. 